\title{
Investigation and Optimization of Hello Message Interval for Scalable Ad-Hoc Network
}

\author{
Shailendra Singh Tomer \\ M.tech student \\ Electronics \& communication Department \\ MIT Bhopal
}

\author{
Achint Chugh \\ Professor \& Head of department \\ Electronics \& communication Department \\ MIT Bhopal
}

\begin{abstract}
Mobile A d h o c Networks (MANET) has become an exciting and important technology in recent years because of the rapid proliferation of wireless devices. A mobile ad-hoc network alive of mobile nodes that can move freely in an open environment. Communicating nodes in a MANET usually seek the help of other intermediate nodes to establish communication channels. manet contain reactive protocols Aodv is one of popular protocol. Route failure due to motion of nodes and lack of battery power thus route maintance is an important issue routing is an important function aspect in wireless ad-hoc network that handles discovering and maintaining the path beween nodes within a network.For route maintance the node periodically broadcast hello message to their neighbours.In aodv although benefits of these messages have been proven ,many study show some drawback for these message.In paper we optimize the hello interval with different hello loss 2 or 3.The simulation is done on Qualnet .Result analy sis determine that Aodv perform better at $\mathrm{HI}=3 \mathrm{sec}$
\end{abstract}

\section{Keywords}

MANET,aodv protocol,hello message,hello interval

\section{INTRODUCTION}

Mobile Ad-hoc Network is a network without infrastructure, where every node works as a router. In this network, every node must discover its local neighbours and through those neighbours it will communicate to nodes that are out of its transmission range (multi-hop). These networks suffer from nodes mobility causes continual link breaks. This causes the routing protocol to use different techniques to update its knowledge about local neighbours, which is known as Local Connectivity organize (LCM). One of those techniques is periodically broadcasting short beacon messages (called hello messages). Although continual broadcasting the hello messages helped to get clearer view of the local network topology, it also produced some drawbacks for the whole inter connection in general. Rising number of these messages consumes the network resources and bandwidth, increases interferences with data and control messages, and utilizes the limited nodes battery life during sending and receiving operations $[4,5,6,7]$. On the other hand, the decreased number of hello messages results in time gap between link failure event and its identification. In reality, it means that, the protocol designer has to trade-off sending these messages carefully to represent the real needs for connectivity updating. In this study, we attempt to adaptively optimize the maximum time period that can transpire before the node broadcast the next hello message[1,2]. Optimization of this time directly affects the number of sent hello messages during a fixed period of time. Optimization is based on the correlation between the topology reconstruction and the periodical interval for the hello message transmission.

\subsection{Overvie w of AODV}

AODV is an on-demand routing protocol where routes are established only as required. When a route is required, it uses a route discovery process to understand a route. Once it confirm a route, it is maintained as long as it requires by a maintenance method. if a route is not in use, it lapse after a particular point $[9,10,11,13]$. It can use one of the two procedures for link failure detection: link layer feedback or beacon messages. Due to difficulty in obtaining link layer response, it uses beacon messages for ad hoc network as fig 1 $\& 9$ shows.

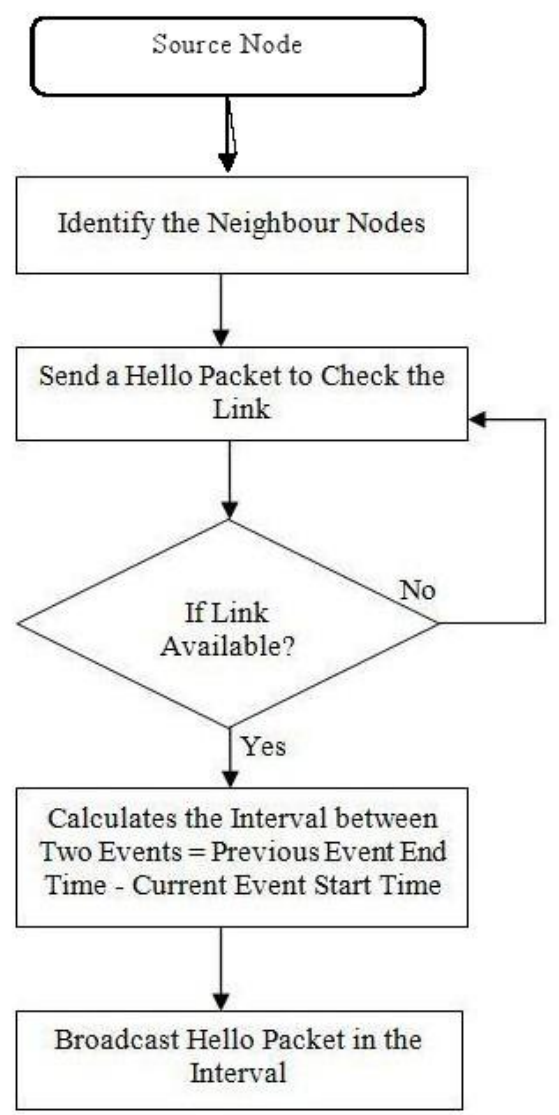

Fig 1: Flow diagram for adaptive hello messaging scheme[9]

i. Active route- A path towards a destination that has a routing table data that is checked as valid path. Only active routes can be used to forward data bundles. 
ii. Relay- Relaying or Broadcasting means transmission of the Internet Protocol. A relayed data bundles may not be forwarded without knowing destination address, but Relaying is useful to enable scattering of AODV messages throughout the ad hoc network.

iii. Destination- An Internet Protocol address to which data bundles are to be transmitted. Same as "destination node". A node knows it is the destination node for a typical data bundles when its address appears in the correct field of the Internet Protocol header. Routes for destination nodes are supplied by action of the AODV protocol, which carries the Internet Protocol address of the destination node in route discovery messages.

iv. Feed Forwarding Point - A intersection that allows to forward bundles destined for another point, by retransmitting them to a next level that is closer to the unicast destination along a path that has been set up using routing messages.

v. Forward route- A route set up to forward data bundles from a point originating a Route Discovery operation towards its desired destination.

vi. Invalid route-A route that has no longer exist, denoted by a state of invalid in the routing table entry. An invalid route is used to hold previously valid route information for an time interval. An invalid route cannot be used to forward data bundles, but it can gives information beneficial for route organises, and also for future RREQ messages.

vii. Source point- A points that starts an AODV route discovery message to be processed and possibly retransmitted by other nodes in the ad hoc network. For sample, the node starting a Route finding process and relaying the RREQ message is called the origin ating point of the RREQ message.

viii. Backward route- A route set up to forward a reply (RREP) bundles back to the Source from the destination or from an intermediate point having a route to the destination.

ix. Sequence number- A monotonically increasing number maintained by each source node. In AODV routing messages, it is used by other nodes to determine.

\section{LITERATURE REVIEW}

Essam Natsheh et al.[5], Adaptive Optimizing of Hello Messages in Wireless Ad-Hoc Networks. They used fuzzy logic system to optimize the frequency of sending hello messages.

R.Gokila et al.[10], An Efficient Secure Data Transmission for Adaptive Hello Messaging Scheme in Manet.He used design decreases the energy consumption and delay without any major difference in throughput.

Ian D.Chakeres et al[6], have examined the effectiveness of hello messages for monitoring link status and found some influencing factors on the utility of these messages.
Perkins et al. [3], creators of AODV protocol, discussed the reasons for applying hello messages with AODV and presented some disadvantages for using these messages. They mentioned that they will investigate their ways to eliminate drawbacks of these messages. Hello messages frequency optimization can allow us to get its benefits and at the same time remove its disadvantages, which will be proven during this research.

Shaily Mittal et al [12], PERFORMANCE COMPARISION OF AODV, DSR and ZRP ROUTING PROTOCOLS IN MANET'S. according them AODV shows best results in measuring end to end delay and packet delivery ratio.

Satish K. Shah et al. [11], Development and Simulation of Artificial Neural Network based decision on parametric values for Performance Optimization of Reactive Routing Protocol for MANET using Qualnet.

P. Divyal et al.[9], An Adaptive Hello Messaging and Multipath Route Maintenance in On-Demand MANET Routing Protocol by reduce battery drain through practical suppression of unnecessary Hello messaging. presented. The proposed mechanism depends on using a history table to record the topology changes and according to the frequency of these changes the announcement rate is calculated.

Lundgren et al. [7] have provided evidence that the unreliable implementation of hello messages can lead to a systematic mismatch between the route state and the actual connectivity status. This field of mismatch is defined as "communication gray areas ". In such areas, data bundles cannot be transfer to each other. although the beacon messages indicate neighbor reachability.

Teresa Albero-Albero et al.[13] Salvador Santonja-Climent, Víctor-M.Sempere- Payá, JordiMataix-Oltra,"AODV Performance Evaluation and Proposal of Parameters Modification for Multimedia Traffic on Wireless Ad hoc Networks

\subsection{Comparison of Protocols}

Though table 1 AODV has good throughput than OLSR and DSR because of promiscuous listening and aggressive route caching policy always has an edge in high density network. AODV is better than DSR because AODV replies too the first arrived RREQ packet and discard other RREQ which arrive later from other source. In DSR, during data transfer, ip address of each node added successively, hence making jitter time to rise. On the other hand AODV has no such problem and hence has low jitter delay. Furthermore, Aodv suites application where End to End to End delays are very critical. As a reactive protocol AODV transmits network information only on demand. The finite proactive part is the route maintenance (hello message).the AODV protocol is loop free and avoid the counting to infinity problem by the use of sequence numbers. This protocol offer quick adaption to mobile network with low processing and low bandwidth utilization fig 2 to 8 simulation results show comparatively of routing protocols easily. The number of data bytes successfully send to the receiver end during a particular amount of time is indicate throughput $\&$ the ratio of the number of delivered data bundles to the destination. This gives the level of delivered data bundles to the destination known as packet delivery fraction. 
Table $1 \mathrm{~S}$ cenario 1(fig 8) for comparison of protocols

\begin{tabular}{|c|c|}
\hline PARAMETERS & TYPE \\
\hline terrain & $1500 X 1500$ \\
\hline Routing protocol & AODV,DRS \& OLSR \\
\hline Channel & Wireless \\
\hline Packet size & 512 \\
\hline Packet to send & 5000 \\
\hline Traffic type & CBR \\
\hline Radio propagation Model & Two Ray Ground \\
\hline Mobility model & Random waypoint \\
\hline Number of nodes & 30 \\
\hline Simulation time & $300 \mathrm{~s}$ \\
\hline
\end{tabular}

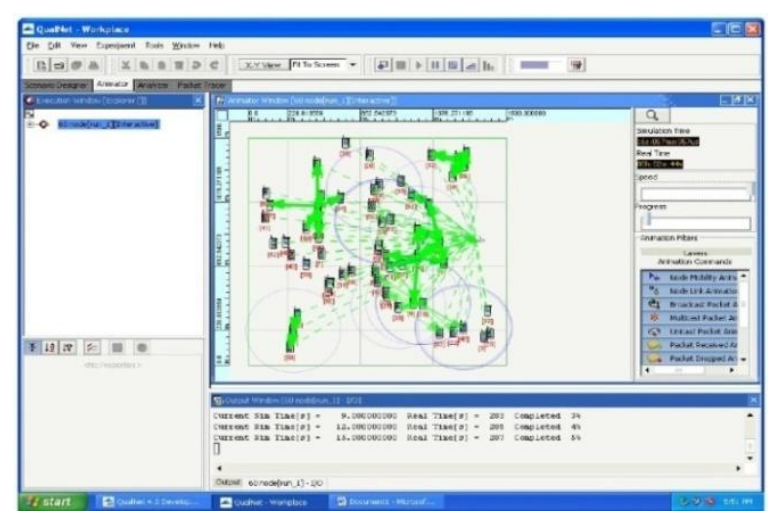

Fig 2:Qualnet Scenario 1

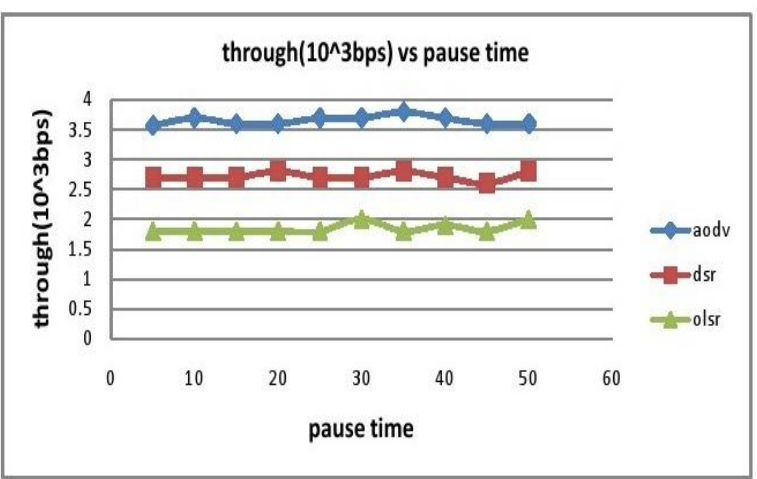

Fig 3: Throughput effect on pause time

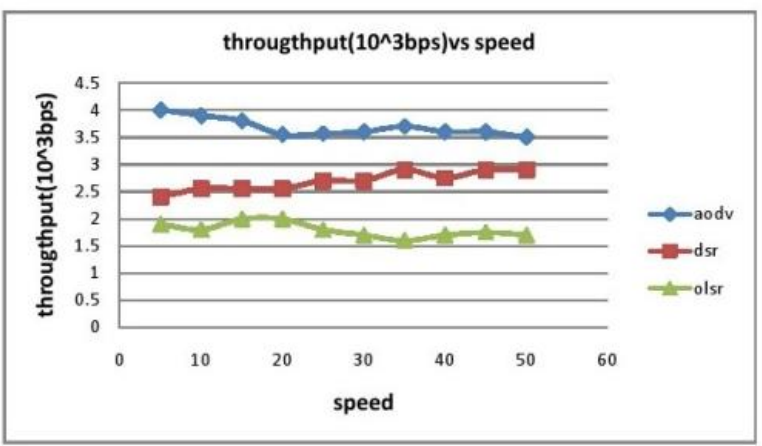

Fig 4: throughput effect vs Speed

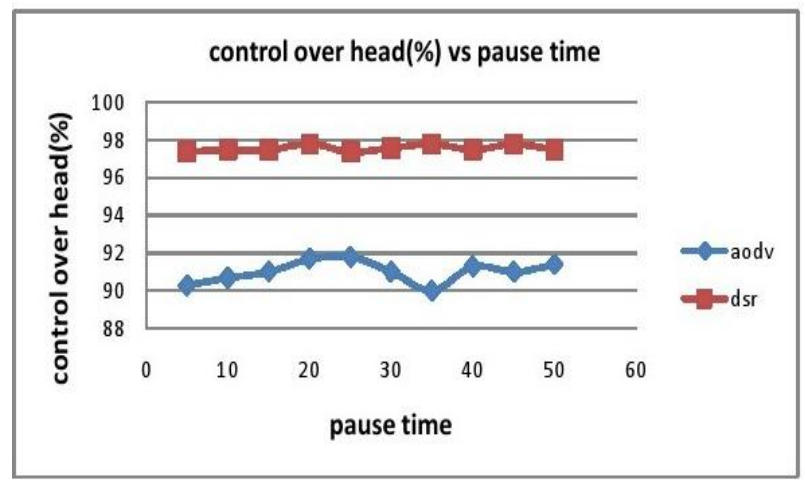

Fig 5: control over head effect on pause time

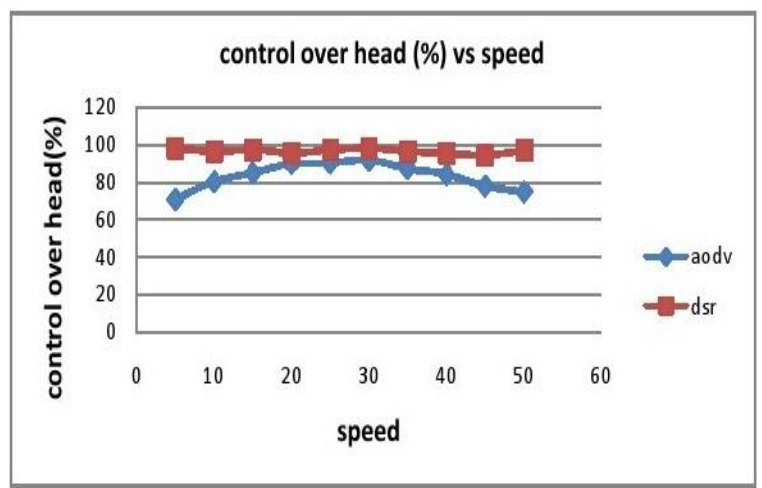

Fig 6: control over head effect on speed

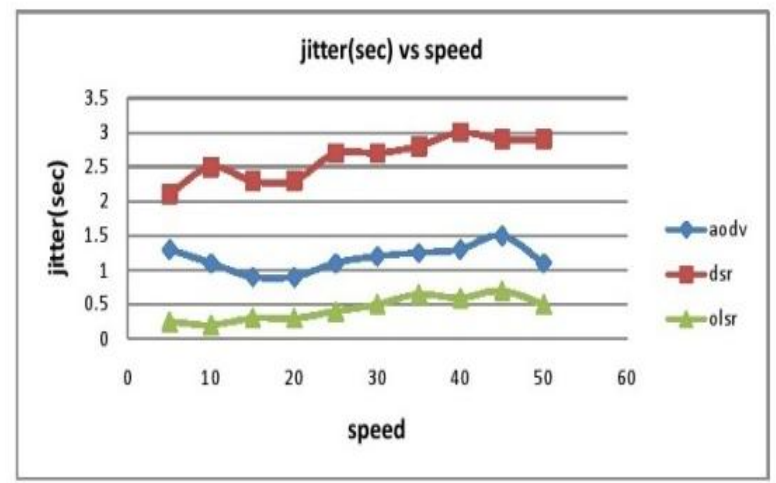

Fig 7: jitter effect on speed

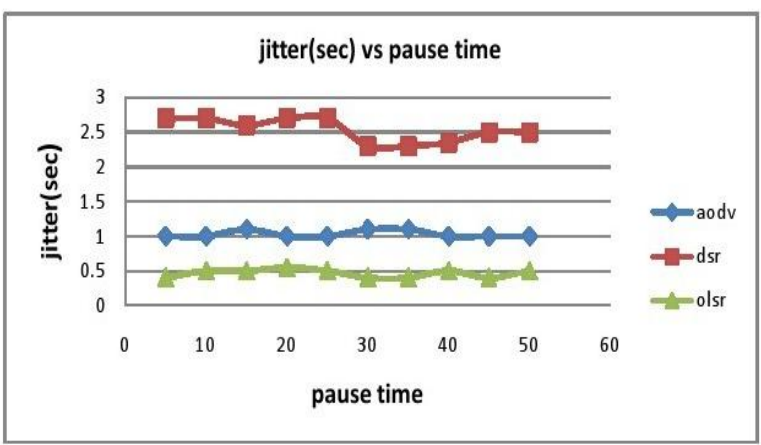

Fig 8: jitter effect on pause time 


\section{METHODOLOGY}

A node determines connectivity information by listening hello messages from its set of neighbours. A node should use hello messages only if it is part of active route.

In this section we first present our network model and then formulate optimization hello interval for scalable ad-hoc network. We consider aodv, dsr \& olsr protocols under MANET operating within random network topology and random work station. Work station mobility follows a model, there are many mobility models used in the evaluation of AODV protocol. The random way point model is one the most commonly used mobility models for simulations of protocols. In this model, each node selects a random destination, uniformly distributed within the two-dimensional space. In conventional hello messaging scheme before a packet is sent, status of neighbour nodes should be recognized first so as to recognize if there is a link failure with one of its neighbouring workstation. If the workstation moves to an area where no active nodes are in its neighbourhood, then nodes keeps broadcasting beacon messages and due to this unnecessarily energy consumption takes place. So if we choose best comfortable protocol which give u better throughput quick response we found aodv is best one by comparing AODV DSR \& OLSR protocols which we can show by given results by graphs (fig 2 to 7). Now the efficiency of Aodv can be better than by default value by optimizing hello interval in hello message under different speed \& pause time in aodv by default hello loss value is 2 but it can we 3 for optimization of aodv.value could not be beyond 2 or 3 . The maximum interval of time between the transmissions of hello messages is hello interval. , time during which the node should assume that link is currently broken is the time if a node does not receive any packet from that node within the given time i.e. $\mathrm{tfd}=($ allowed_hello_loss)*(hello_interval). (1)

by default, allowed_hello_loss is equal to 2 and hello_interval is equal to $1^{\wedge} 3 \mathrm{~ms}$ i.e. $1 \mathrm{sec}$ for aodv . now in the dynamic hello messaging scheme the time for link failure detection (tfdd) is given as:

tfdd $=($ allowed_hello_loss-.5)*(hello_interval) $(2)$

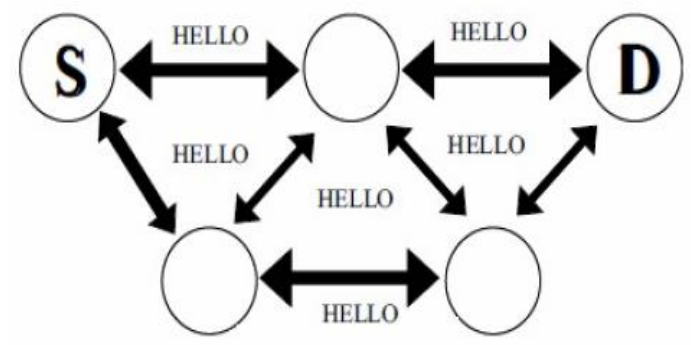

Fig 9: routing process in aodv protocol

First by using table 2 we check it without hello message (means 0 second hello interval) it give best result but it is not practically possible due to drawback like economic factor, battery or uncertainty behaviour of node ,power etc .then check it with hello message [hello message status- yes, beacon interval= $(1 \mathrm{sec}, 1.5 \mathrm{sec}, 2 \mathrm{sec}, 2.5 \mathrm{sec}, 3 \mathrm{sec})]$.If the value of hello interval goes down or we used fuzzy logic or any artificial interval for minimize hello interval the unnecessary number of hello massage are increase nodes continuously send message that by load or traffic is increase that effect communication.Here idea is to optimize adov by changing value of hello interval it could be 0 to 3 second the result can analy sis by given graphs \& data which is obtain by using QUALNET SIMULATOR in different scenario.fig $(10,11,12)$ show running stage model of simulation in different mode.

\section{RESULT \& DISCUSSION}

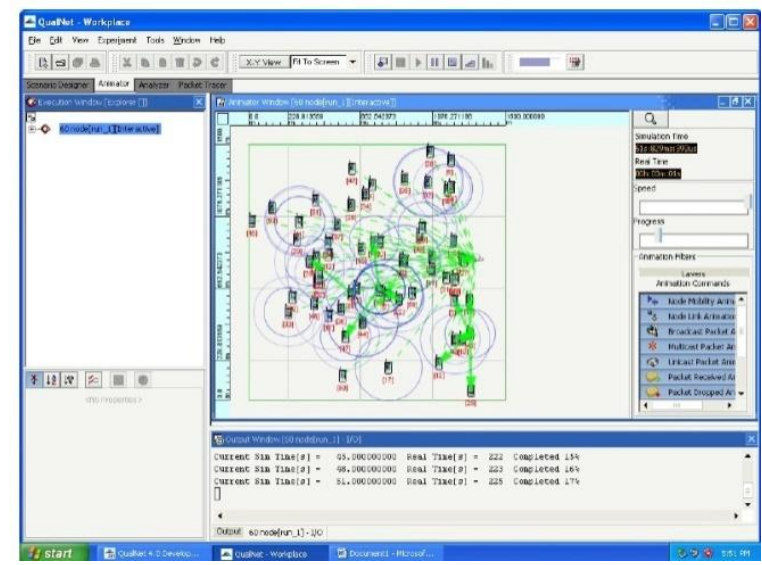

Fig 10: Qualnet Scenario 2

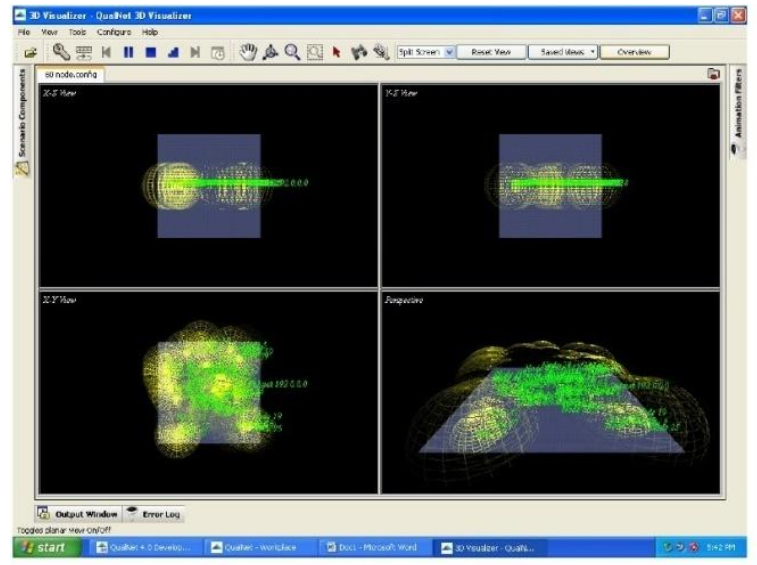

Fig 11: Animation Effect on active routing nodes

Packet Delivery Fraction-the ratio of the number of send data packet to the receiver end. This gives the level of delivered data bundles to the destination.

End point-to-End point Delay-the time taken by a data bundles to arrive in the receiver end. It also includes the delaying occured by path or route finding process and the queue in data bundles transmission. Only the data bundles that successfully send to destinations that counted.

Throughput-The number of data bytes successfully send to the receiver end during a particular amount of time (s).

Packet delivery ratio : the ratio of the number of delivered data bundles to the destination. This gives the level of delivered data bundles to the destination.

$\sum$ Number of data bundles receive / $\sum$ Number of data bundles send

The more value of data bundle delivery ratio means the excellent performance of the protocol.

End point-to-end point Delay : the mean time taken by a data bundles to arrive in the destination. It also includes the delay caused by path or route discovery process and the queue 
in data bundles transmission. Only the data bundles that successfully delivered to destinations that counted.

$\sum$ ( arrive time - send time ) / $\sum$ Number of connections

The lesser value of end point to end point delay means the good performance of the protocol.

Packet Lost : the total number of packets dropped during the simulation.

Packet lost $=$ Number of packet send - Number of packet received .

The lesser value of the data bundles lost means the excellent performance of the protocol.

Control over head - it is the number if routing control packets sent by the protocol. sometimes expressed as a ratio of control to data indication of how effectly a routing protocol operates

Control over

head $=[($ RREQ + RREP+RERR $) /($ RREQ + RREP + RERR $+D A T$

A PACKETS) $]^{*} 100$

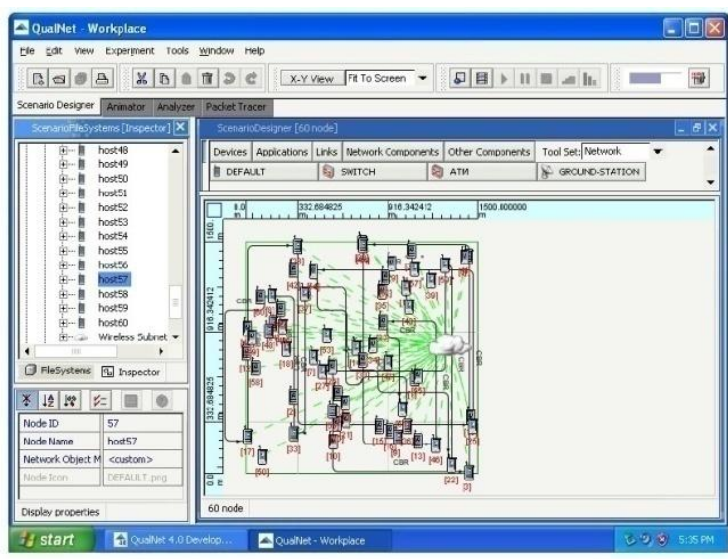

Fig 12: Qualnet running stage scenario 3
Table $2 \mathrm{~S}$ cenario for AODV hello message utilization with hello interval ( $0-3 \mathrm{sec})$

\begin{tabular}{|c|c|}
\hline PARAMETERS & TYPE \\
\hline terrain & 1500 X1500 \\
\hline Routing protocol & AODV \\
\hline Channel & Wireless \\
\hline Packet size & 512 \\
\hline Packet to send & 6000 \\
\hline Traffic type & CBR \\
\hline Radio propagation Model & Two Ray Ground \\
\hline Mobility model & Random way point \\
\hline Number of nodes & 60 \\
\hline Nuber of cbr links & 15 \\
\hline Simulation time & 300 s \\
\hline allow hello loss & $2 \& 3$ \\
\hline
\end{tabular}

AODV is one the most important protocol reactive routing protocol which show these result in compare to other protocol Even AODV is best protocol but still its utilization limited for more improvement we change different value of different parameter of AODV here we discussing about hello message to make it adaptive utilization.

We check these results on cases below:

1. Low speed with constant pause time (50 s)

2. High speed with constant pause time $(50 \mathrm{~s})$

3. Low pause time with constant speed $(2 \mathrm{mps})$

4. High pause time with constant speed (20 mps )

After $t$ AODV Protocol gives best result on with hello message condition (mean hello interval 0 second) mean hello message are not active. But in with beacon message compare to $(1 \mathrm{sec}, 1.5 \mathrm{sec}, 2 \mathrm{sec}, 2.5 \mathrm{sec}, 3 \mathrm{sec})$ these we observer hello interval 3 second that point AODV gives best result.fig 13 shows thses resuls according table 2 parameter

Note - we increase hello interval more than 3 second than hello message goes to zero means proper communication will not happened $($ means sent item $=$ receive item $=$ almost zero)

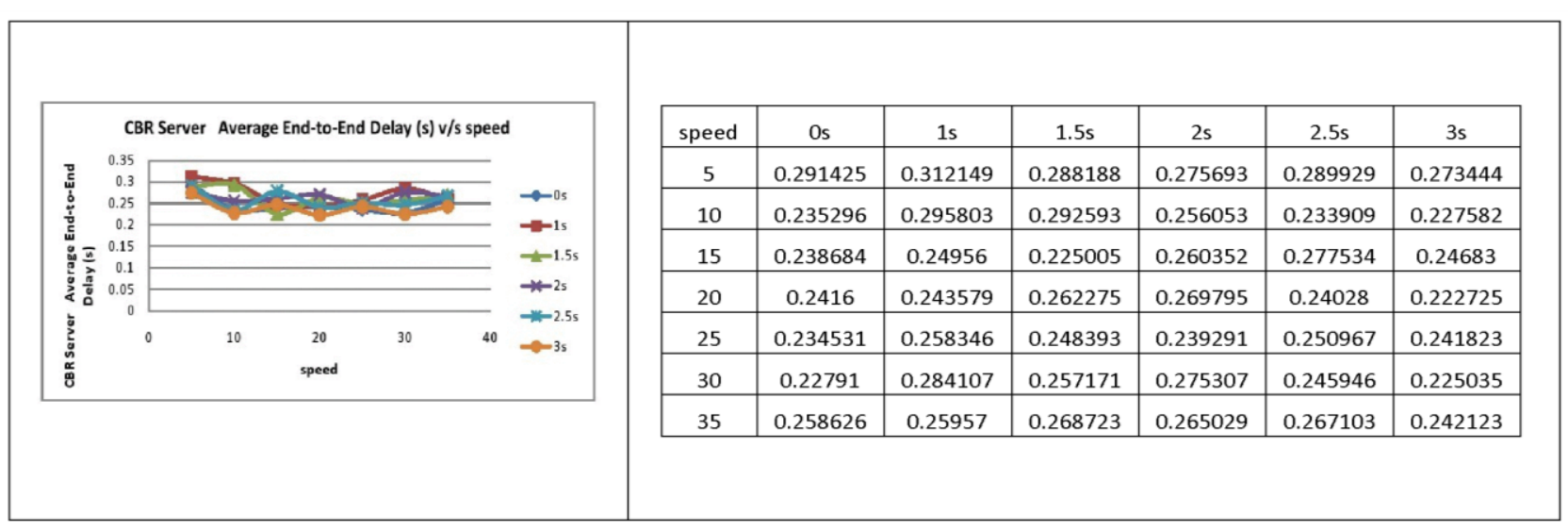




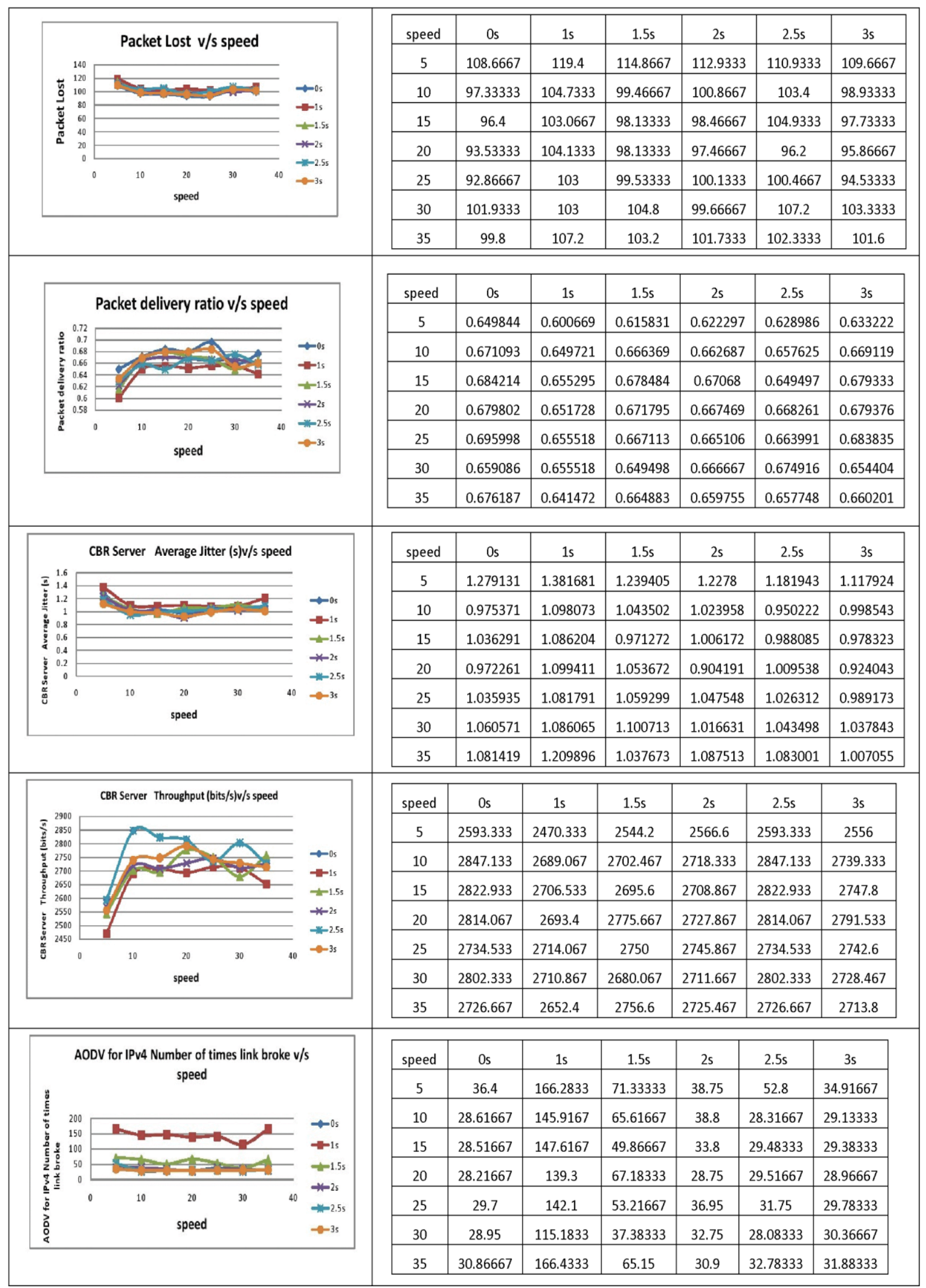

Fig 13: comparison of hello interval with constant pause time 


\section{CONCLUSION}

Any routing protocol gives excellent result if through put is high ,end to end delay is low ,jitter is also low, number of link break are low, packet loss is low \& (PDR) packer delivery ratio is high, these are most important parameter to check out the performance or optimization. As per the simulation results, we have observed that in highly mobile habital use of hello message in particular interval helps us to get better PDR than without using hello message, in our paper we found if hello interval in 3 second with allow hello loss 2or 3 give better result than previous one mean compare to other hello intervals that thing shows by simulation results \& graphs so this one can help us in future to better communication on real time situation fig 14 shows overall summary of simulation results.

To increase utilization of hello message, hello message interval should be up to the mark three second with hello loss between $2 \& 3$.

\begin{tabular}{|c|c|c|c|c|c|}
\hline $\begin{array}{c}\text { AODV } \\
\text { Parameter }\end{array}$ & $\begin{array}{c}\text { With hello } \\
\text { message } \\
\text { (HI=1 second) }\end{array}$ & $\begin{array}{c}\text { With hello } \\
\text { message }\end{array}$ & $\begin{array}{l}\text { With hello } \\
\text { message } \\
\text { (HI=2 second) }\end{array}$ & $\begin{array}{c}\text { With hello } \\
\text { message } \\
(\mathrm{HI}=2.5 \text { second })\end{array}$ & $\begin{array}{l}\text { With hello } \\
\text { message } \\
\text { (HI=3 second) }\end{array}$ \\
\hline Through put & LOW & LOW & LOW & LOW & HIGH \\
\hline $\begin{array}{l}\text { End to end } \\
\text { delay }\end{array}$ & HIGH & $\mathrm{HIGH}$ & HIGH & HIGH & LOW \\
\hline jitter & HIGH & HIGH & HIGH & HIGH & LOW \\
\hline Packet loss & HIGH & HIGH & $\mathrm{HIGH}$ & HIGH & LOW \\
\hline $\begin{array}{c}\text { Number of link } \\
\text { break }\end{array}$ & HIGH & $\mathrm{HIGH}$ & HIGH & HIGH & LOW \\
\hline PDR & LOW & LOW & LOW & LOW & HIGH \\
\hline
\end{tabular}

Fig 14 Overall S ummary of Simulation Result

\section{REFERENCES}

[1] A. E. Gamal, C. Nair, B. Prabhakar, E. Uysal-Biyikoglu, and S. Zahedi, "Energy-efficient scheduling of packet transmissions over wireless networks," Proceedings of the Twenty-First Annual Joint Conference of the IEEE Computer and Communications Societies (INFOCOM), vol. 3, New York, NY, June 23-27 2002, pp. 1773-1782.

[2] C. Bettstetter, "On the minimum node degree and connectivity of awireless multihop network," Proceedings of the third ACM International Symposium on Mobile Ad Hoc Networking and Computing (MOBIHOC), Lausanne, Switzerland, June 9-11 2002

[3] C. E. Perkins and E. M. Royer. The Ad hoc On-Demand Distance Vector Protocol. In C. E. Perkins, editor, Ad hoc Networking, pages 173.219. Addison-Wesley, 2000.

[4] C. Srisathapornphat and C. -C. Shen, "Coordinated power conservation for ad hoc networks," Proceedings of the IEEE International Conference on Communications (ICC), vol. 5, New York, NY, Apr 2002, pp. 3330-3335.

[5] Essam Natsheh, Adznan Jantan, Sabira Khatun, and Shamala Subramaniam, jully 2007," Adaptive Optimizing of Hello Messages in Wireless Ad-Hoc Networks "

[6] Honolulu, Hawaii, October 2002)

[7] I. D. Chakeres and E. M. Belding-Royer. The Utility of Hello Messages for Determining Link Connectivity. In Proceedings of the 5th International Symposium on Wireless Personal Multimedia Communications (WPMC

[8] L. Buttyan and J. P. Hubaux, "Enforcing service availability in mobile ad hoc WANs," Proceedings of the first ACM international symposium on Mobile and ad hoc networking \& computing (MOBIHOC), Boston, Massachusetts, 2000, IEEE Press, pp. 87-96.

[9] M. Maleki, K. Dantu and M. Pedram, "Power-aware source routing protocol for mobile ad hoc networks," Proceedings of the 2002 international symposium on Low power electronics and design, Monterey, California, USA, 2002, ACM Press, pp. 72-75.

[10] P. Divya1,s.hemlata ,2013" An Adaptive Hello Messaging and Multipath Route Maintenance in OnDemand MANET Routing Protocol"

[11] R.Gokila 2014," An Efficient Secure Data Transmission for Adaptive Hello Messaging Scheme in Manet"

[12] Satish K Shah, "Development and Simulation of Artificial Neural Network based decision on parametric values for Performance Optimization of Reactive Routing Protocol for MANET using Qualnet" in Proceeding of International conference "Computational Intelligence And Communication Networks CICN 2010" as well as on IEEE website pp :167-171, 26-28 Nov 2010

[13] Shaily Mittal , Prabhjot Kaur,2009 “PERFORMANCE COMPARISION OF AODV, DSR and ZRP ROUTING PROTOCOLS IN MANET'S',

[14] Teresa Albero-Albero, Salvador Santonja-Climent, Víctor-M.Sempere- Payá, JordiMataix-Oltra,“AODV Performance Evaluation and Proposal of Parameters Modification for Multimedia Traffic on Wireless Ad hoc Networks 